\title{
Preliminary validation of a calf-side test for diagnosis of failure of transfer of passive immunity in dairy calves
}

\author{
I. Elsohaby* ${ }^{1}$ and G. P. Keefe* \\ *Department of Health Management, Atlantic Veterinary College, University of Prince Edward Island, Charlottetown, Prince Edward Island, \\ Canada C1A 4P3 \\ †Infectious Diseases, Department of Animal Medicine, Faculty of Veterinary Medicine, Zagazig University, Zagazig City 44511, Sharkia Province, \\ Egypt
}

\section{ABSTRACT}

The objective of this study was to evaluate the utility of an initial version of a calf-side test (ZAPvet Bovine IgG test, ZBx Corp., Toronto, ON, Canada) for diagnosis of failure of transfer of passive immunity (FTPI) in dairy calves. Blood samples $(n=202)$ were collected from calves from 1 to $11 \mathrm{~d}$ of age. Serum $\operatorname{IgG}$ concentration was determined by radial immunodiffusion (RID) assay. The mean IgG concentration was $1,764 \pm$ $1,035 \mathrm{mg} / \mathrm{dL}$, with a range from 133 to $5,995 \mathrm{mg} / \mathrm{dL}$. The ZAPvet Bovine IgG test was used to assess FTPI (serum $\operatorname{IgG}<1,000 \mathrm{mg} / \mathrm{dL}$ ) and test characteristics were calculated. The number of samples that had FTPI from the RID assay and ZAPvet test was 55 and 96 samples, resulting in a true prevalence of $27 \%$ and an apparent prevalence of $47.5 \%$, respectively. The sensitivity, specificity, and positive and negative predictive values of the ZAPvet test were $0.82,0.65,0.47$, and 0.91 , respectively. The results of the ZAPvet test were derived from 2 observers, and the overall level of agreement between the results of the 2 observers was $84 \%$, with a kappa value of 0.67 . The ZAPvet Bovine IgG test showed good potential for further development as a cost-effective, rapid calf-side test for monitoring FTPI in dairy calves.

Key words: failure of transfer of passive immunity, radial immunodiffusion assay, calf-side, ZAPvet Bovine IgG test

\section{INTRODUCTION}

Newborn calves are born agammaglobulinemic, without circulating $\operatorname{Ig} G$, and they depend on the passive transfer of $\mathrm{IgG}$ from maternal colostrum provided within the first hours of life (Smith et al., 1964). Calves that fail to ingest or absorb sufficient colostral IgG, resulting in a serum IgG concentration $<1,000 \mathrm{mg} /$

Received October 28, 2014

Accepted March 10, 2015.

${ }^{1}$ Corresponding author: ielsohaby@upei.ca
dL, suffer from failure of transfer of passive immunity (FTPI; Vogels et al., 2013).

Failure of transfer of passive immunity in dairy calves is a significant problem (Fecteau et al., 2013) and is considered a predisposing risk factor for most early neonatal infectious disease losses and long-term productivity losses in heifers. Effects of FTPI include decreased milk yield and increased culling rates in firstlactation animals (Tyler et al., 1996b; Godden, 2008). The reported prevalence of FTPI in dairy calves in North America ranged from 19 to 40\% (Nocek et al., 1984; Dairy NAHMS; USDA, 2007). Having calves with lower levels of passive immunity has major economic consequences for dairy producers (Trotz-Williams et al., 2008), including reduced calf daily gains (Robison et al., 1988), increased morbidity and mortality, increased production costs, and reduced profitability (Morin et al., 1997; Jaster, 2005). Therefore, monitoring of FTPI rates can identify herd management deficiencies and ensure timely detection and medical interventions, which are important to reduce the risk of associated diseases among calves and the economic impact for dairy producers (Furman-Fratczak et al., 2011).

Several assays are available to assess passive immunoglobulin transfer status in newborn calves (Tyler et al., 1996a; Parish et al., 1997; Weaver et al., 2000). The radial immunodiffusion (RID) assay is the reference standard method for determining passive immunoglobulin transfer by measuring the quantity of IgG in the serum (Weaver et al., 2000; Godden, 2008). The RID assay is time consuming and cannot be performed by producers or veterinarians on farm, because it is a laboratory procedure that requires trained laboratory technicians. The procedure takes 18 to $24 \mathrm{~h}$ to obtain results and requires advanced technical skill to perform the assay and measure zones of precipitation accurately; moreover, it is not amenable to automation (Liu et al., 2007). Additionally, RID uses reagents with a limited shelf life and is often more expensive than indirect assay methods (Riley et al., 2007; Bielmann et al., 2010). Imprecision in RID assay replicates from the same sample have been noted and are attributed 
to inconsistencies in the assay standards (Ameri and Wilkerson, 2008). Other than RID, serum total protein determination using refractometry, sodium sulfite turbidity test, zinc sulfate turbidity test, ELISA, serum $\gamma$-glutamyl transferase activity, and whole-blood glutaraldehyde coagulation test have been described with varying degrees of accuracy for predicting IgG concentrations in calves (Tyler et al., 1996a; Parish et al., 1997; Weaver et al., 2000). The turbidimetric immunoassay described by Etzel et al. (1997) performed well in calves (Dawes et al., 2002; Alley et al., 2012) and foals (Davis et al., 2005). However, these assays require specific instruments and specially trained personnel to interpret the data.

Therefore, methods for accurate, rapid, convenient, and cost-effective calf-side diagnosis and simple monitoring of FTPI in calves are needed. The ZAPvet Bovine IgG Test (ZBx Corporation, Toronto, ON, Canada) is intended to be a fast and simple on-farm test to confirm adequate passive transfer of immunity (APTI) in calves. The ZAPvet Bovine IgG Test uses 2 visual lines, a test line and a reference line, to provide a semiquantitative determination of the concentration of bovine IgG using whole blood, plasma, or serum samples. The ZAPvet Bovine IgG Test was developed using calibrators with turbidimetric-determined concentrations. The ZAPvet test is inexpensive and rapid; it requires no instruments, reagents, or buffers, and therefore can be performed anywhere and at any time. The objective of this study was to describe the test characteristics of the initial version of a ZAPvet Bovine IgG test against RID and to measure interobserver variation for assessing FTPI in dairy calves.

\section{MATERIALS AND METHODS}

\section{Serum Samples}

Holstein calves $(\mathrm{n}=202)$ from 5 commercial dairy herds in Prince Edward Island and 1 herd in Nova Scotia were sampled between June and October 2013. Whole blood was collected from 1- to 11-d-old calves by jugular venipuncture, using a 20-gauge, 1-inch hypodermic needle (BD Vacutainer Precision Glide, Becton Dickinson Co., Franklin Lakes, NJ), into a sterile, plastic Vacutainer tube without anticoagulant (BD Vacutainer, Becton Dickinson Co.). Samples were transported on ice in a cooler to the Maritime Quality Milk Laboratory, University of Prince Edward Island (UPEI). Serum was separated by centrifugation at $1,500 \times g$ for $10 \mathrm{~min}$ at $\sim 20^{\circ} \mathrm{C}$ within $5 \mathrm{~h}$ of collection. Three aliquots of serum were collected and stored at $-80^{\circ} \mathrm{C}$. Serum from Nova Scotia samples was separated by similar centrifugation methods at a local veterinary clinic and then frozen at $-20^{\circ} \mathrm{C}$ until transport to UPEI. This study was conducted in accordance with the Canadian Council on Animal Care (CCAC) guidelines (CCAC, 2009) under a protocol (No. 6005332) approved by the Animal Care Committee at UPEI.

\section{RID Assay (Reference Standard)}

Serum samples were allowed to thaw at room temperature (20 to $24^{\circ} \mathrm{C}$ ) and vortexed for $10 \mathrm{~s}$. Subsequently, IgG was measured by RID (Bovine IgG RID Kit, Triple J Farms, Bellingham, WA). The RID assay was performed according to the manufacturer's instructions, using $5 \mu \mathrm{L}$ of undiluted serum sample in each well. Plates with the same lot number were used on all RID assays to reduce variability (standard deviation) in the assay results. The diameter of precipitated rings was measured using a hand-held caliper after 18 to 24 $\mathrm{h}$ of incubation at room temperature. Each sample and assay standard was tested in replicates of 5 . The averages of the 5 replicates of the assay standards were used to build a calibration curve that was subsequently used to determine IgG concentrations for the serum samples. The final IgG concentration for each sample was determined by calculating the average of the 5 replicates. Serum samples with IgG concentrations greater than the manufacturer's stated performance range for the assay $(>3,000 \mathrm{mg} / \mathrm{dL})$ were diluted (50:50) with deionized sterile water and retested.

\section{ZAPvet Bovine IgG Test}

Serum samples were thawed at room temperature and vortexed for $10 \mathrm{~s}$ before being tested by ZAPvet Bovine IgG test (ZBx Corp.). The ZAPvet test uses 2 visual lines, a test line and a reference line, to provide a semiquantitative determination of the concentration of bovine IgG in serum samples (Figure 1). The ZAPvet test was performed according to manufacturer's instructions. Undiluted serum $(35-40 \mu \mathrm{L})$ was added to the sample application zone. The test was kept on a flat surface and incubated at room temperature for 15 to 20 min, and then read by comparing the intensity of the test line to the reference line (Table 1). The result was interpreted by 2 observers. Observer 1 (student) did the initial test reading and took a digital photo at the time of interpretation. The photo was sent to observer 2 (ZBx scientist) for interpretation.

\section{Statistical Analysis}

Statistical analysis was performed using Stata software (Stata Corporation, 2013), with results considered significant at $P<0.05$. The analysis was performed in 


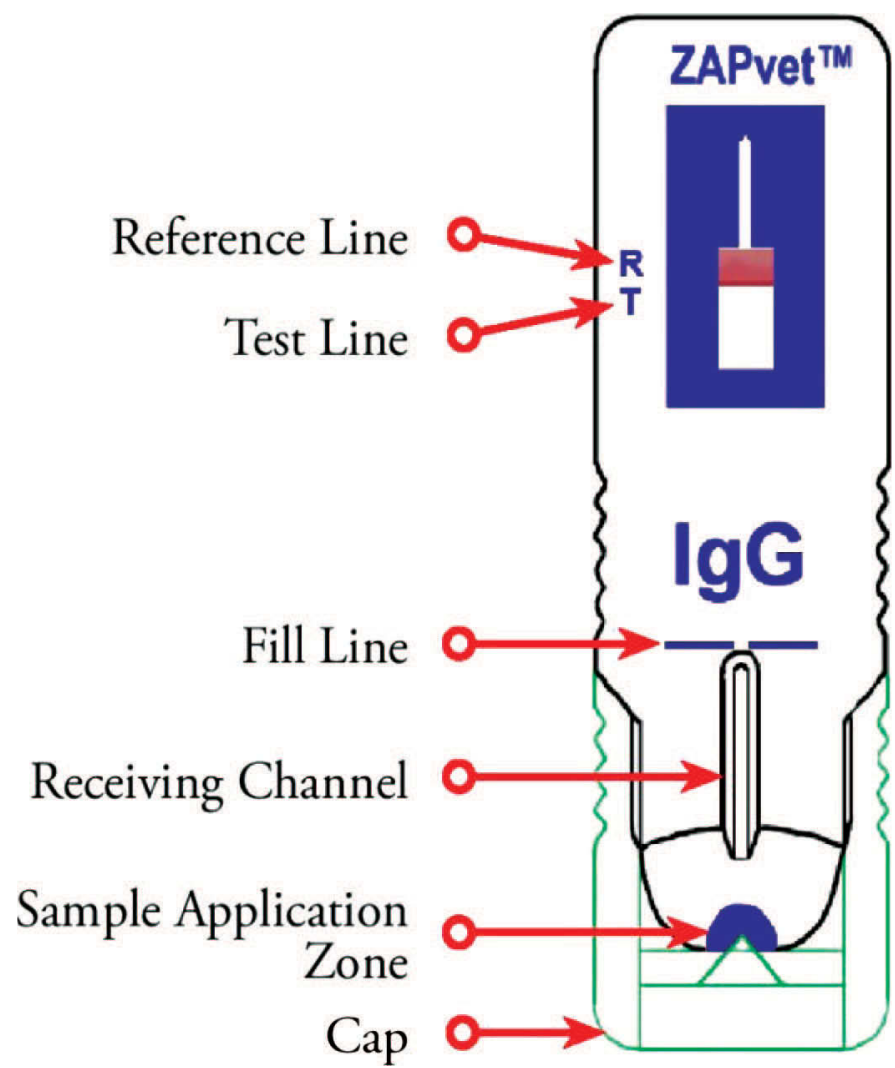

Figure 1. Illustration of the ZAPvet Bovine IgG test (ZBx Corp., Toronto, ON, Canada). Note: cap is removed for direct collection. Color version available online.

3 stages. First, the test characteristics of the ZAPvet Bovine IgG test for diagnosis of FTPI in dairy calves were calculated using $2 \times 2$ tables (diagt command in Stata). Sensitivity (Se) was defined as the proportion of calves with FTPI, as determined by RID, that were classified as positive on ZAPvet test. Conversely, specificity (Sp), was defined as the proportion of calves without FTPI that were classified as negative on ZAPvet test. Accuracy was defined as the proportion of calves that were correctly classified by the ZAPvet test. The predictive values of a test are dependent upon the Se and Sp of the test and the prevalence of disease in the study population (Dohoo et al., 2009). To examine the performance of the ZAPvet test in different populations with varying degrees of FTPI, the positive (PPV) and negative (NPV) predictive values were calculated for prevalence estimates ranging from 1 to $100 \%$. The PPV was the proportion of ZAPvet test-positive calves that truly had FTPI, and the NPV was the proportion of ZAPvet test-negative calves that did not have FTPI. Second, the test characteristics of the ZAPvet Bovine $\mathrm{IgG}$ test were assessed at different test-line intensities (weaker, similar, and stronger), based on results de-
Table 1. Interpretation of test-line intensity of the ZAPvet Bovine IgG test (ZBx Corp., Toronto, ON, Canada) corresponding to IgG concentrations measured by the radial immunodiffusion (RID) assay (Triple J Farms, Bellingham, WA)

\begin{tabular}{lcl}
\hline $\begin{array}{l}\text { ZAPvet } \\
\text { test-line } \\
\text { intensity }\end{array}$ & $\begin{array}{l}\text { RID test: } \\
\operatorname{IgG}(\mathrm{mg} / \mathrm{dL})\end{array}$ & $\begin{array}{l}\text { of passive of transfer } \\
\text { (FTPI) }\end{array}$ \\
\hline Weaker & $<1,000$ & Positive \\
Similar & 1,000 to 2,000 & $\begin{array}{l}\text { Negative } \\
\text { Stronger }\end{array}$ \\
\hline
\end{tabular}

rived from observer 1 (Table 1 ), followed by calculation of percentage agreement with the RID assay. Finally, the level of agreement between results of the ZAPvet test derived from the 2 observers were assessed using McNemar's test (Lachenbruch and Lynch, 1998) for paired data to check for bias, followed by calculation of the kappa statistic.

\section{RESULTS}

\section{RID Assay}

The mean $( \pm \mathrm{SD})$ for IgG concentrations of the serum samples $(\mathrm{n}=202)$ as obtained by RID were $1,764 \pm$ $1,035 \mathrm{mg} / \mathrm{dL}$ (ranging from 133 to $5,995 \mathrm{mg} / \mathrm{dL}$ ). The number of samples with IgG concentrations below a cut-off value of $1,000 \mathrm{mg} / \mathrm{dL}$ for FTPI-positive cases was 55 out of 202 samples (Figure 2), which generated a true FTPI prevalence of $27 \%$.

\section{ZAPvet Bovine IgG Test}

Agreement with RID. The number of samples with test-line intensity weaker than the reference line ( $\operatorname{IgG}$ $<1,000 \mathrm{mg} / \mathrm{dL}$ ) was 96 out of 202 samples for observer 1 , resulting in an apparent FTPI prevalence of $47.5 \%$. The ZAPvet test results derived from observer 1 correctly identified $45(82 \%)$ calves as FTPI positive and misclassified $10(18 \%)$ calves as FTPI negative that had IgG concentrations of $<1,000 \mathrm{mg} / \mathrm{dL}$ on RID (false negative, $\mathbf{F N}$ ). A false positive (FP) result occurred in $51(35 \%)$ calves that were FTPI negative and had IgG concentrations $>1,000 \mathrm{mg} / \mathrm{dL}$, according to RID (Table $2)$. The mean $( \pm S D)$ for IgG concentration of FN and FP samples on RID were $866 \pm 139 \mathrm{mg} / \mathrm{dL}$, with range of 568 to $996 \mathrm{mg} / \mathrm{dL}$ and $1,746 \pm 579 \mathrm{mg} / \mathrm{dL}$, with a range of 1,014 to $3,415 \mathrm{mg} / \mathrm{dL}$, respectively (Figure 3 ).

Observer 2 identified 83 out 202 calves as having FTPI, resulting in an apparent FTPI prevalence of $41 \%$. The ZAPvet test results interpreted by observer 2 correctly classified 40 (73\%) of the FTPI-positive calves and misclassified $15(27 \%)$ calves as negative (FN). These 15 calves had a mean IgG concentration of 832 
Table 2. Agreement between radial immunodiffusion assay (RID; Triple J Farms, Bellingham, WA) and the ZAPvet bovine IgG test (ZBx Corp., Toronto, ON, Canada) for diagnosis of failure of transfer of passive immunity (FTPI; IgG $<1,000 \mathrm{mg} / \mathrm{dL}$ ) in 202 dairy calves based on results derived from 2 observers ${ }^{1}$

\begin{tabular}{|c|c|c|c|c|c|}
\hline \multirow[b]{3}{*}{ RID test } & \multicolumn{5}{|c|}{ ZAPvet test ${ }^{2}$} \\
\hline & \multicolumn{2}{|c|}{ Observer 1} & \multirow[b]{2}{*}{ Total } & \multicolumn{2}{|c|}{ Observer 2} \\
\hline & $\mathrm{T}+$ & $\mathrm{T}-$ & & $\mathrm{T}+$ & $\mathrm{T}-$ \\
\hline $\mathrm{T}+$ & 45 & 10 & 55 & 40 & 15 \\
\hline $\mathrm{T}-$ & 51 & 96 & 147 & 43 & 104 \\
\hline Total & 96 & 106 & 202 & 83 & 119 \\
\hline
\end{tabular}

${ }^{1}$ Values in bold indicate disagreement between the 2 tests, resulting in the misclassification of a calf with FTPI.

${ }^{2}$ Observer $1=$ student; observer $2=\mathrm{ZBx}$ scientist; $\mathrm{T}+=$ test positive; $\mathrm{T}-=$ test negative.

$\pm 166 \mathrm{mg} / \mathrm{dL}$ on RID with a range of 568 to $996 \mathrm{mg} /$ dL. False-positive results occurred in $43(29 \%)$ calves, which had a mean IgG concentration of $1,730 \pm 564$ $\mathrm{mg} / \mathrm{dL}$ on RID with a range of $1,014-3,415 \mathrm{mg} / \mathrm{dL}$.

Test Characteristics and Predictive Values. Table 3 presents the test characteristics of the ZAPvet Bovine IgG test, including Se, Sp, PPV, and NPV. Accuracy of the ZAPvet test was determined for the assessment of FTPI ( $\operatorname{IgG}<1,000 \mathrm{mg} / \mathrm{dL})$ based on the results derived from the 2 observers. The PPV was relatively low, whereas NPV was higher for both observers. Figure 4 shows the predictive ability of the ZAPvet test at various prevalences of FTPI ranging from 1 to $100 \%$.

Performance at Different Test-Line Intensities. Using the observations from observer 1, the numbers of samples with test-line intensity weaker ( $\operatorname{IgG}$ $<1,000 \mathrm{mg} / \mathrm{dL}$ ), similar (between 1,000 and 2,000 mg/
$\mathrm{dL})$, and stronger $(>2,000 \mathrm{mg} / \mathrm{dL})$ than the reference line were $96(47.5 \%), 98(48.5 \%)$, and $8(4 \%)$, respectively. The test characteristics of the ZAPvet test at weaker, similar, and stronger test intensities are presented in Table 4.

Interobserver Variations. Table 5 presents the FTPI determination interobserver agreement of 2 observers using the ZAPvet test. The overall percentage agreement was $84 \%$, with a corresponding kappa value of 0.67 . The percentage positive agreement was $69 \%$. McNemar's test for the Se comparison between the 2 observers showed no significant difference $(P=0.18)$ between proportions of calves classified as having FTPI by the 2 observers. McNemar's test for the Sp comparison between the 2 observers also showed no significant difference $(P=0.15)$ between proportions of calves classified as having ATPI.

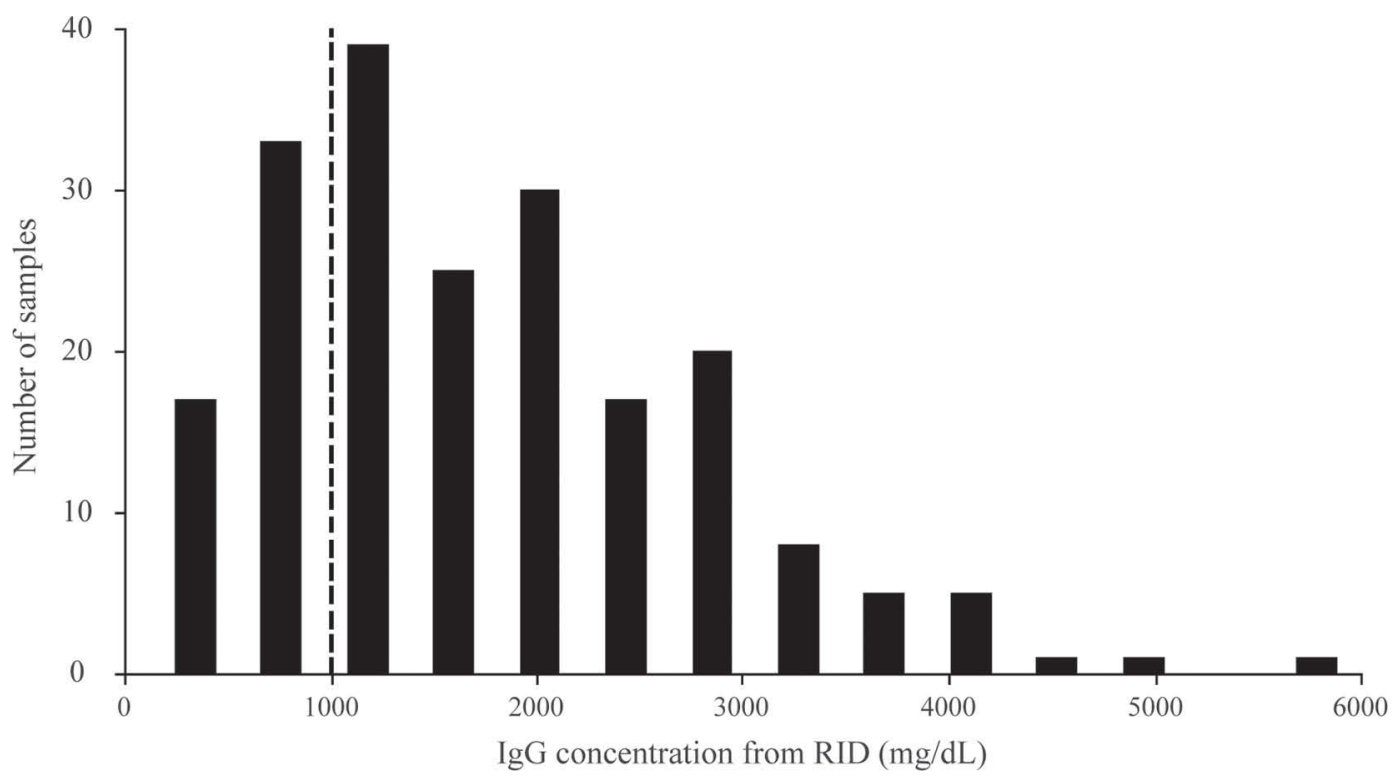

Figure 2. Histogram of the distribution of serum IgG concentrations for 202 calves, measured by the radial immunodiffusion (RID) assay (Triple J Farms, Bellingham, WA). The dashed line represents the cut-off value for failure of transfer of passive immunity positive cases (IgG $<1,000 \mathrm{mg} / \mathrm{dL})$. 
Table 3. Test characteristics (95\% CI in parentheses) and predictive values of the ZAPvet Bovine IgG test (ZBx Corp., Toronto, ON, Canada) for assessment of failure of transfer of passive immunity (IgG $<1,000 \mathrm{mg} / \mathrm{dL}$ ) in 202 dairy calves based on results derived from 2 observers

\begin{tabular}{lll}
\hline & \multicolumn{2}{c}{ ZAPvet test } \\
\cline { 2 - 3 } Test characteristic & & \multicolumn{2}{c}{ Observer 1} & Observer 2 \\
\hline Prevalence & 0.475 & 0.41 \\
Sensitivity & $0.82(0.69-0.91)$ & $0.73(0.59-0.84)$ \\
Specificity & $0.65(0.57-0.73)$ & $0.71(0.63-0.78)$ \\
Positive predictive value & $0.47(0.37-0.57)$ & $0.48(0.37-0.59)$ \\
Negative predictive value & $0.91(0.83-0.95)$ & $0.87(0.80-0.93)$ \\
Accuracy & 0.70 & 0.71 \\
\hline
\end{tabular}

${ }^{1}$ Accuracy $=$ number of correctly classified calves.

\section{DISCUSSION}

Failure of transfer of passive immunity in dairy calves is associated with high morbidity and mortality. Monitoring of FTPI rates can identify herd management deficiencies, which are important to reduce the risk of associated diseases among calves (Furman-Fratczak et al., 2011). Therefore, a calf-side method with high Se is essential to correctly identify calves with FTPI for action such as additional monitoring and intervention. The ZAPvet test had reasonably high Se $(82 \%)$ and, as a result, dairy producers and veterinarians will be able to confirm ATPI in their calves on farms or in private veterinary clinics. Moreover, the ZAPvet test will give an indication of the prevalence of FTPI in the herd and will identify deficiencies in the colostrum management practices. Estimates of within-farm prevalence can be used to motivate producers to take action with respect to colostrum management and to monitor the effectiveness of changes in management. The Se and Sp of the ZAPvet test were very close to the Se $(87 \%)$ and Sp $(69 \%)$ detected for the same samples using optical refractometry in our laboratory with the same study population (data not shown) and were similar to previous reports on refractometry (Deelen et al., 2014). The Se and Sp of the ZAPvet test were somewhat lower than those calculated for an automated turbidimetric immunoassay; however, that test is not currently available for cow-side use (Etzel et al., 1997; Dawes et al., 2002; Alley et al., 2012).

Using the ZAPvet test to assess FTPI in dairy calves has some advantages compared with refractometry. Once the serum sample is obtained, refractometry can diagnose FTPI in less than $15 \mathrm{~s}$, but very few dairy farms have access to a centrifuge to separate serum. In this study, the ZAPvet test assessed FTPI using serum, but whole blood and plasma could also be used. This means that producers could take a blood sample and apply the ZAPvet test directly to ensure ATPI in their calves on farm. Validation of the ZAPvet test for diagnosis of FTPI using whole blood is warranted. There is no initial investment for producers to begin monitoring FTPI with the ZAPvet test. Consumable costs for the

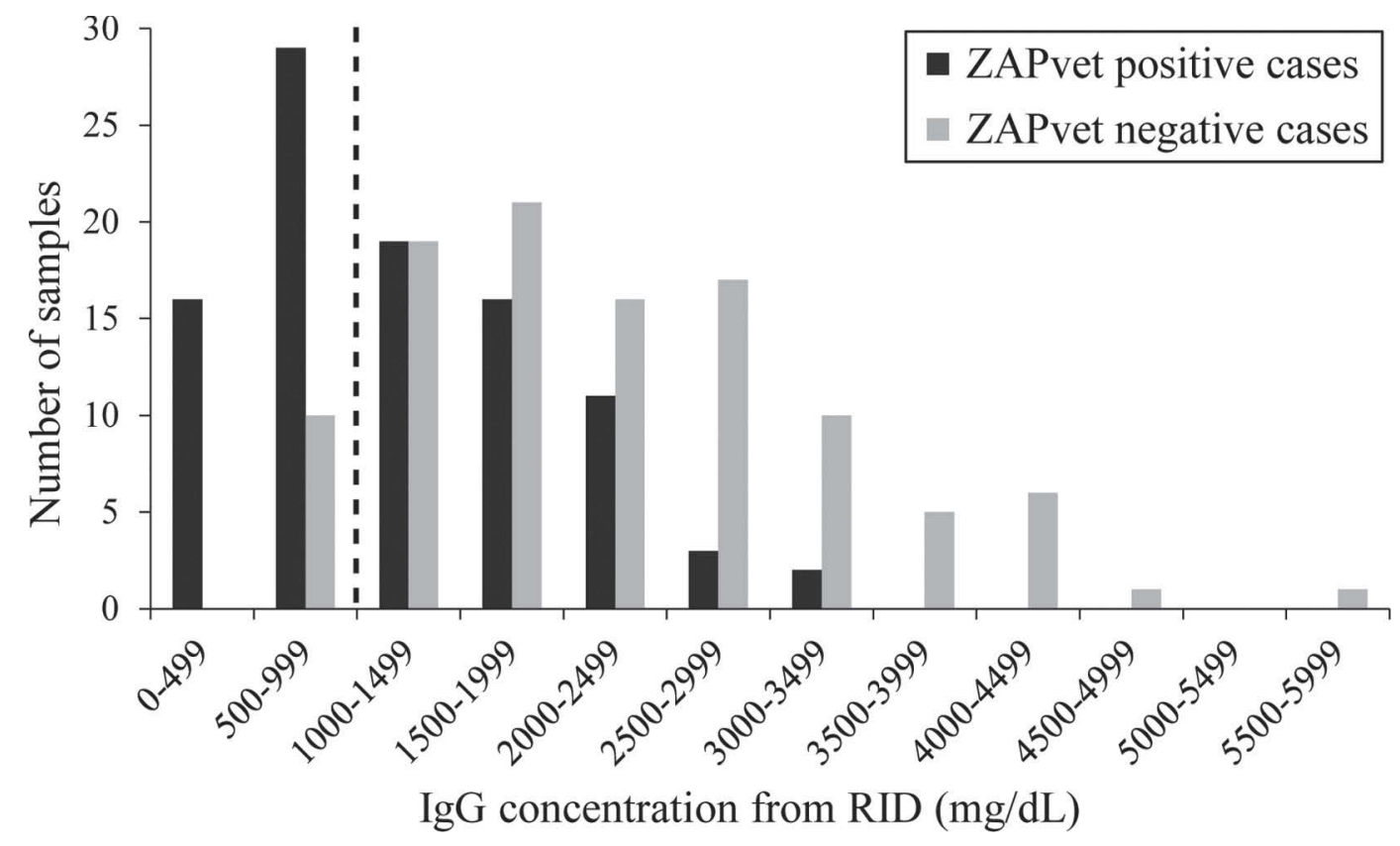

Figure 3. Histogram of the distribution of the ZAPvet Bovine IgG test (ZBx Corp., Toronto, ON, Canada) results derived from observer 1 for diagnosis of failure of transfer of passive immunity (FTPI) in 202 calves, against serum IgG concentrations measured by radial immunodiffusion (RID) assay (Triple J Farms, Bellingham, WA). The dashed line represents the cut-off value for FTPI positive cases (IgG $<1,000 \mathrm{mg} / \mathrm{dL}$ ). 
Table 4. Test characteristics and predictive values (no./total in parentheses) of the ZAPvet Bovine IgG test (ZBx Corp., Toronto, ON, Canada) at different test-line intensity levels

\begin{tabular}{lcccc}
\hline & \multicolumn{3}{c}{ Test characteristic } \\
\cline { 2 - 5 } Test-line & & & Positive & Negative \\
intensity & Sensitivity & Specificity & predictive value & predictive value \\
\hline Weaker & $0.82(45 / 55)$ & $0.65(96 / 147)$ & $0.47(45 / 96)$ & $0.91(96 / 106)$ \\
Similar & $0.52(39 / 75)$ & $0.54(68 / 127)$ & $0.40(39 / 98)$ & $0.65(68 / 104)$ \\
Stronger & $0.10(7 / 72)$ & $0.99(129 / 130)$ & $0.88(7 / 8)$ & $0.67(129 / 194)$ \\
\hline
\end{tabular}

test are estimated at Can $\$ 5$ to $\$ 8$, depending on the marketing channel. In comparison, the upfront cost to begin monitoring with a refractometer is approximately Can $\$ 350$.

In the test population, the ZAPvet test correctly diagnosed the majority of FTPI cases, with a relatively low number of FN (10 samples). The FN samples had IgG concentrations measured by RID between 568 to $996 \mathrm{mg} / \mathrm{dL}$; that is, close to $1,000 \mathrm{mg} / \mathrm{dL}$ (Figure 3), indicating only partial FTPI and perhaps posing a lower risk of morbidity and mortality (Lee et al., 2008; Fecteau et al., 2013). The Sp (65\%) of the ZAPvet test was moderate, with a relatively high number of FP (51 samples). Sixteen of $51 \mathrm{FP}$ samples had IgG concentrations measured by RID between 1,014 and 1,260 mg/dL (Figure 3), which is very close to $1,000 \mathrm{mg} / \mathrm{dL}$. Several factors could explain the discrepancy between ZAPvet and RID results. It is well known that immunoassays are affected by many factors. First, different antibodies were used by the 2 assays. The RID standards are made using adult bovine serum $\left(\operatorname{IgG}_{1}\right.$ and $\left.\operatorname{IgG}_{2}\right)$, whereas the ZAPvet test was made using calf serum (mainly $\operatorname{IgG}_{1}$; Butler, 1983). Changing the antibodies could greatly affect the result (Tate and Ward, 2004). Second, RID itself has substantial variability. The literature has shown that RID assays provided by different manufactures could give results that differ by as much as $40 \%$. This is thought to be due to differences in the standards used to determine calibration curves (Ameri and Wilkerson, 2008). Considering the high degree of variation between RID assays provided by different manufacturers, the difference between ZAPvet and RID

Table 5. Interobserver agreement for ZAPvet Bovine IgG test ( $\mathrm{ZBx}$ Corp., Toronto, ON, Canada) results derived from 2 observers for assessment failure of transfer of passive immunity in 202 dairy calves ${ }^{1}$

\begin{tabular}{|c|c|c|c|}
\hline \multirow[b]{2}{*}{ Observer 1} & \multicolumn{2}{|c|}{ Observer 2} & \multirow[b]{2}{*}{ Total } \\
\hline & $\mathrm{T}+$ & $\mathrm{T}-$ & \\
\hline $\mathrm{T}+$ & 73 & 23 & 96 \\
\hline $\mathrm{T}-$ & 10 & 96 & 106 \\
\hline Total & 83 & 119 & 202 \\
\hline
\end{tabular}

${ }^{1} \mathrm{~T}+=$ test positive; $\mathrm{T}-=$ test negative. in the current study is acceptable. In this study, each sample was tested in replicates of 5 by RID assay to minimize variations, whereas only 1 replicate was used for the ZAPvet test. The mean coefficient of variation for the 5 replicates tested by RID method was $7.8 \%$ (data not shown).

The Sp of the ZAPvet test might be improved with recalibration of the device, but this is likely to come at a cost of lower Se. The relative importance of FP versus FN diagnoses and the predictive values in relevant populations should be considered before recalibration. In North America, the reported prevalence of FTPI in dairy calves ranges from 19 to 40\% (Nocek et al., 1984; Dairy NAHMS; USDA, 2007). Figure 4 illustrates the predictive values of a positive or negative ZAPvet test across populations with varying prevalences of FTPI. When the proportion of calves with FTPI increased, NPV decreased. For example, at a low prevalence of $19 \%$ and a high prevalence of $40 \%$, the NPV of the ZAPvet test was 94 and $84 \%$, respectively. Translating the NPV to the probability that a ZAPvet test-negative calf truly has FTPI is referred to as the positive predictive value of a negative test (PPVN) and is equal to 1 NPV (Dohoo et al., 2009). Subsequently, the proportion of calves with FTPI that would not receive treatment would be very small (6\%) for low-prevalence herds and relatively large $(16 \%)$ for high-prevalence herds.

The PPV of the ZAPvet test was relatively low and, as a result, a substantial number of calves with ATPI will be classified as having FTPI. Compared with the overall cost of the disease, which is estimated at Can $\$ 1,105$ per affected calf (Stilwell and Carvalho, 2011), the cost of a false-positive FTPI diagnosis is relatively low at the calf level; very young calves (before complete gut closure) might receive additional colostrum or colostral supplements, as well as more intense monitoring for early intervention if disease occurs. At the herd level, although prevalence may be overestimated, the relative effect of changes in management should be apparent, even if the predictive ability for individual animals is less than ideal.

The level of agreement between results derived from observer 1 (student) and observer 2 (ZBx scientist) was 


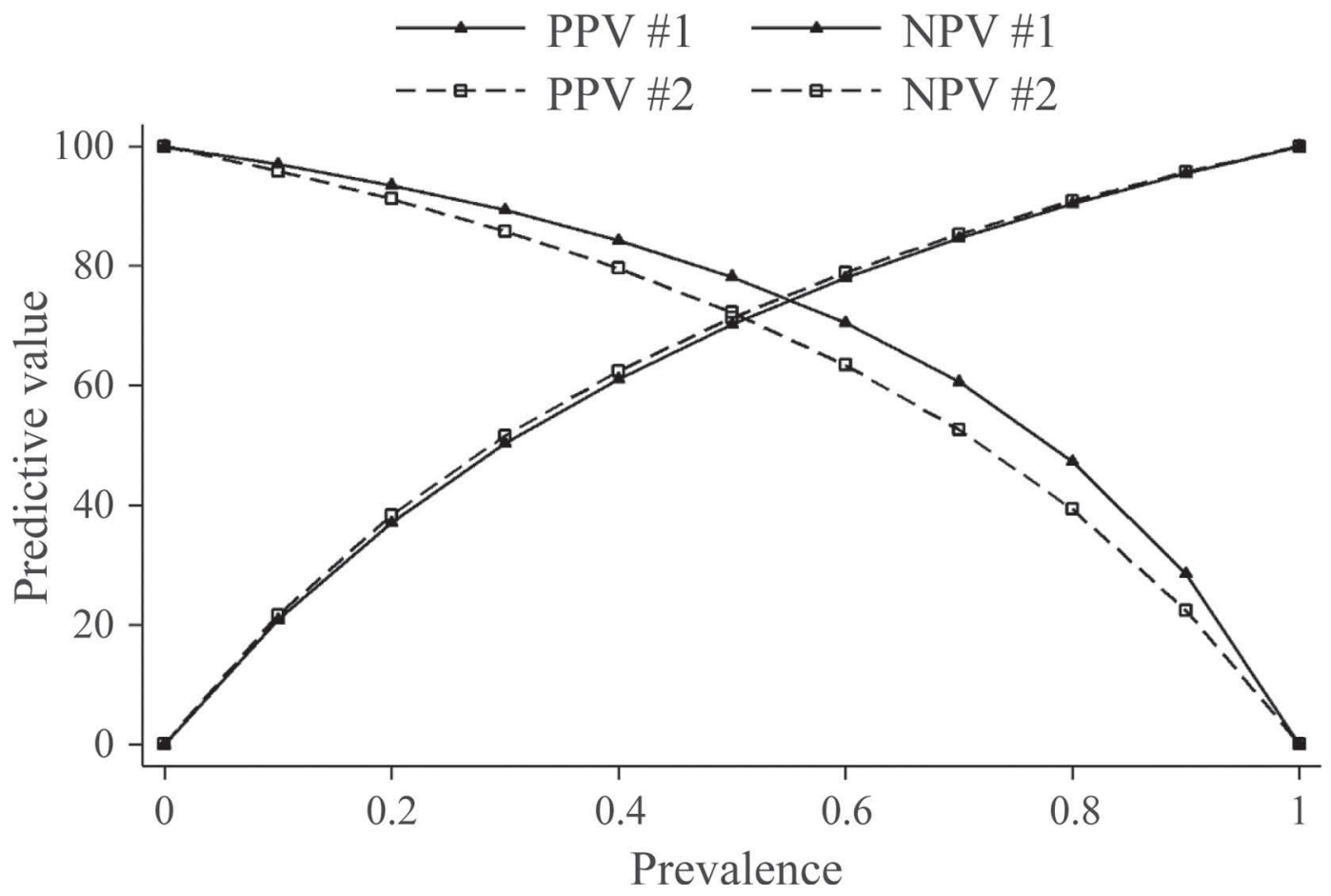

Figure 4. Positive predictive values (PPV) and negative predictive values (NPV) for the ZAPvet Bovine IgG test (ZBx Corp., Toronto, ON, Canada) based on results derived from 2 observers (\#1 and \#2) for diagnosis of failure of transfer of passive immunity (IgG $<1,000 \mathrm{mg} / \mathrm{dL}$ ) in 202 dairy calves.

high (84\%), with a kappa value of 0.67 , which indicates substantial agreement. This indicates that the 2 observers agreed on classification of calves with respect to calves with FTPI and ATPI (Table 5). The test characteristics of the ZAPvet test based on observer 1 and observer 2 derived results were very close (Figures 3 and 4), in agreement with McNemar's test, which showed nonsignificant difference $(P>0.05)$ between proportions of calves classified as having FTPI and ATPI by the 2 observers. The process of interpretation of test-line intensity compared with the reference line was made easy by the provision by the manufacturer of example photos for completed ZAPvet tests for samples with different IgG concentrations ranging from 115 to $3,200 \mathrm{mg} / \mathrm{dL}$. Consequently, producers are able to perform the ZAPvet test with minimal training.

\section{CONCLUSIONS}

Preliminary data suggest that the ZAPvet Bovine IgG test has potential for monitoring FTPI on farms or in veterinary clinics. The ZAPvet test is relatively sensitive and would be acceptable as an initial screening test for diagnosis of FTPI in dairy calves; it is more efficient than submitting serum samples to an accredited veterinary diagnostic laboratory for $\operatorname{IgG}$ testing. However, the low specificity of ZAPvet test would result in overprediction of FTPI incidence, which could result in unnecessary interventions for calves with ATPI. Furthermore, studies to validate the ZAPvet test for diagnosis of FTPI using whole blood samples are warranted.

\section{ACKNOWLEDGMENTS}

The authors thank Natasha Robinson (Maritime Quality Milk Laboratory, Charlottetown, PEI, Canada) for her technical assistance and data collection. Alan Fredeen and Jennafer Bent from Dalhousie Agriculture Campus (Truro, Nova Scotia) provided the Nova Scotia samples. In addition, the authors thank ZBx Corporation (Toronto, Canada; Patricia Lorenz and Cindy Xu) for providing us with ZAPvet Bovine IgG test devices and for professional interpretation of the test results. The authors thank William Chalmers (Atlantic Veterinary College) for technical assistance in preparation of the manuscript.

\section{REFERENCES}

Alley, M. L., D. M. Haines, and G. W. Smith. 2012. Short communication: Evaluation of serum immunoglobulin G concentrations using an automated turbidimetric immunoassay in dairy calves. J. Dairy Sci. 95:4596-4599. 
Ameri, M., and M. J. Wilkerson. 2008. Comparison of two commercial radial immunodiffusion assays for detection of bovine immunoglobulin G in newborn calves. J. Vet. Diagn. Invest. 20:333-336.

Bielmann, V., J. Gillan, N. R. Perkins, A. L. Skidmore, S. Godden, and K. E. Leslie. 2010. An evaluation of brix refractometry instruments for measurement of colostrum quality in dairy cattle. J. Dairy Sci. 93:3713-3721.

Butler, J. E. 1983. Bovine immunoglobulins: An augmented review. Vet. Immunol. Immunopathol. 4:43-152.

CCAC (Canadian Council on Animal Care). 2009. The care and use of farm animals in research, teaching and testing. CCAC, Ottawa, ON, Canada.

Davis, D. G., D. M. Schaefer, K. W. Hinchcliff, M. L. Wellman, V. E. Willet, and J. M. Fletcher. 2005. Measurement of serum IgG in foals by radial immunodiffusion and automated turbidimetric immunoassay. J. Vet. Intern. Med. 19:93-96.

Dawes, M. E., J. W. Tyler, D. Hostetler, J. Lakritz, and R. Tessman. 2002. Evaluation of a commercially available immunoassay for assessing adequacy of passive transfer in calves. J. Am. Vet. Med. Assoc. 220:791-793.

Deelen, S., T. Ollivett, D. Haines, and K. Leslie. 2014. Evaluation of a brix refractometer to estimate serum immunoglobulin G concentration in neonatal dairy calves. J. Dairy Sci. 97:3838-3844.

Dohoo, I., W. Martin, and H. Stryhn. 2009. Screening and diagnostic tests. Pages 85-120 in Veterinary Epidemiologic Research, 2nd ed. University of Prince Edward Island, Charlottetown, PEI, Canada.

Etzel, L. R., R. E. Strohbehn, and J. K. McVicker. 1997. Development of an automated turbidimetric immunoassay for quantification of bovine serum immunoglobulin G. Am. J. Vet. Res. 58:1201-1205.

Fecteau, G., J. Arsenault, J. Pare, D. C. Van Metre, C. A. Holmberg, and B. P. Smith. 2013. Prediction of serum IgG concentration by indirect techniques with adjustment for age and clinical and laboratory covariates in critically ill newborn calves. Can. J. Vet. Res. 77:89-94.

Furman-Fratczak, K., A. Rzasa, and T. Stefaniak. 2011. The influence of colostral immunoglobulin concentration in heifer calves' serum on their health and growth. J. Dairy Sci. 94:5536-5543.

Godden, S. 2008. Colostrum management for dairy calves. Vet. Clin. North Am. Food Anim. Pract. 24:19-39.

Jaster, E. H. 2005. Evaluation of quality, quantity, and timing of colostrum feeding on immunoglobulin $\mathrm{G}_{1}$ absorption in Jersey calves. J. Dairy Sci. 88:296-302.

Lachenbruch, P. A., and C. J. Lynch. 1998. Assessing screening tests: Extensions of McNemar's test. Stat. Med. 17:2207-2217.

Lee, S. H., J. Jaekal, C. S. Bae, B. H. Chung, S. C. Yun, M. J. Gwak, G. J. Noh, and D. H. Lee. 2008. Enzyme-linked immunosorbent assay, single radial immunodiffusion, and indirect methods for the detection of failure of transfer of passive immunity in dairy calves. J. Vet. Intern. Med. 22:212-218.

Liu, K. Z., A. Man, T. C. Dembinski, and R. A. Shaw. 2007. Quantification of serum apolipoprotein B by infrared spectroscopy. Anal. Bioanal. Chem. 387:1809-1814.
Morin, D. E., G. McCoy, and W. Hurley. 1997. Effects of quality, quantity, and timing of colostrum feeding and addition of a dried colostrum supplement on immunoglobulin $\mathrm{G}_{1}$ absorption in Holstein bull calves. J. Dairy Sci. 80:747-753.

Nocek, J. E., D. G. Braund, and R. G. Warner. 1984. Influence of neonatal colostrum administration, immunoglobulin, and continued feeding of colostrum on calf gain, health, and serum protein. J. Dairy Sci. 67:319-333

Parish, S. M., J. W. Tyler, T. E. Besser, C. C. Gay, and D. Krytenberg. 1997. Prediction of serum IgG1 concentration in Holstein calves using serum gamma glutamyltransferase activity. J. Vet. Intern. Med. 11:344-347.

Riley, C. B., J. T. McClure, S. Low-Ying, and R. A. Shaw. 2007. Use of Fourier-transform infrared spectroscopy for the diagnosis of failure of transfer of passive immunity and measurement of immunoglobulin concentrations in horses. J. Vet. Intern. Med. 21:828-834.

Robison, J. D., G. Stott, and S. DeNise. 1988. Effects of passive immunity on growth and survival in the dairy heifer. J. Dairy Sci. 71:1283-1287.

Smith, V., R. Reed, and E. Erwin. 1964. Relation of physiological age to intestinal permeability in the bovine. J. Dairy Sci. 47:923-924.

StataCorp. 2013. Stata Statistical Software. StataCorp LP, College Station, TX

Stilwell, G., and R. C. Carvalho. 2011. Clinical outcome of calves with failure of passive transfer as diagnosed by a commercially available IgG quick test kit. Can. Vet. J. 52:524-526.

Tate, J., and G. Ward. 2004. Interferences in immunoassay. Clin. Biochem. Rev. 25:105-120.

Trotz-Williams, L. A., K. E. Leslie, and A. S. Peregrine. 2008. Passive immunity in Ontario dairy calves and investigation of its association with calf management practices. J. Dairy Sci. 91:3840-3849.

Tyler, J. W., T. E. Besser, L. Wilson, D. D. Hancock, S. Sanders, and D. E. Rea. 1996a. Evaluation of a whole blood glutaraldehyde coagulation test for the detection of failure of passive transfer in calves. J. Vet. Intern. Med. 10:82-84.

Tyler, J. W., D. D. Hancock, S. M. Parish, D. E. Rea, T. E. Besser, S. G. Sanders, and L. K. Wilson. 1996b. Evaluation of 3 assays for failure of passive transfer in calves. J. Vet. Intern. Med. 10:304307.

USDA. 2007. Part I: Reference of dairy cattle health and management practices in the United States. National Animal Health Monitoring System (NAHMS), USDA:APHIS:VS CEAH, Fort Collins, CO.

Vogels, Z., G. Chuck, and J. Morton. 2013. Failure of transfer of passive immunity and agammaglobulinaemia in calves in southwest Victorian dairy herds: Prevalence and risk factors. Aust. Vet. J. 91:150-158.

Weaver, D. M., J. W. Tyler, D. C. VanMetre, D. E. Hostetler, and G. M. Barrington. 2000. Passive transfer of colostral immunoglobulins in calves. J. Vet. Intern. Med. 14:569-577. 